УДК 37.013.43:378.016

DOI: 10.33184/YVDK-2021-04-30.20

И.Г.Фаткуллин (2. Уфа),

Г.3. Батырова, М.Р. Нуйкина (2. Уфа)

\title{
ТЕОРИЯ И ПРАКТИКА ОБУЧЕНИЯ ИНОСТРАННЫМ ЯЗЫКАМ И ИНОЯЗЫЧНОЙ КУЛЬТУРЕ
}

B cmambе исследуются аспекты обучения иностранным языкам в контексте их неразрывной связи с культурой народа-носителя языка. Приводится развернутая характеристика культурологической парадигмы. Рассмотрены кониепции, определяющче сферу конкретной парадигмы.

Ключевые слова: иностранный язык, иноязычная культура, культурологическая парадигма, концепция, теория и практика обучения, носители языка.

The article examines the aspects of teaching foreign languages in the context of their inseparable connection with the culture of the native-speaking people. A detailed description of the cultural paradigm is given. The concepts that define the scope of a particular paradigm are considered.

Keywords: foreign language, foreign language culture, cultural paradigm, concept, theory and practice of teaching, native speakers.

В условиях инфор мационного общества, когда процессы взаимопроникновения культур значительно усиливаются, знание иностранного языка становится важным ресурсом для академической и профессиональной мобильности совр еменн ого человека, фактором его кон курентоспособн ости, культурного и социального развития.

В теории и практике преподавания иностранного языка сложилось обоснованное понимание того, что язык является неотъемлемой частью культуры народа, символизирующей, как 
утверждает Р.П. Мильруд [Мильруд 2013: 45], культуру его носителей языка.Поэтому понятие культуры имеет решающее значение в исследовании коммуникационных процессов иностранных языков и лингвистического образования.

Противоречия между эволюцией социальной реальности и существующей практикой преподаваниянаходят свое отражение в научных исследованиях, посвященных аспектам модернизации теории и практики преподавания иностранного языка.

Современную образовательную среду отличают такие качества, как открытость образовательного процесса, использование инновационных технологий, современные подходы к обучен ию.

Усложнение образовательной среды вызывает необходимостьне только конкретно-дидактической проработки процесса обучения, но и осмысления методологии,отвечающейсовременной реальности и вызовам тысячелетия, научным представлениями идеям о неразрывной взаимосвязи языка и культуры, и отражения этой культуры в содержан ии преподавания иностранного языка.

Интерпретация культурологической парадигмы как основы обучения основана на понимании парадигмы как методологической категор ии, лежащей в осн ове проектирования и реализации современного образовательного процесса. Пер воначальн ой интерпретацией пон ятия «парадигма» является ее общенаучное понимание как системы значимых научных достижений, по модели которых организуется исследовательская или образовательная практика в той или иной области знаний организованы в определенный исторический период [Тарева 2017: 211].

В современ ном образовательном пространстве доминируют четыре концепции, которые определяют область кон кретн ой парадигмы: когн итивн о-ин формацион ная (традиционная), культурологическая, личностная и компетентностная (осн ованная на навыках).

Последние три концепции разрабатываются в ответ на новый социальный заказ образования, продиктованный требованиями постиндустриального общества. В настоящее время все эти идеи в результате научного развития получили 
статус подходов, которые «встраиваются» в культурологическую парадигму преподавания иностранного языка, позволяют идентифицировать и применять их в преподавании, используя принцип взаимодополняемости. Культур ологический подход выделяется в этой серии как основной, наиболее общий, связанный с пониманием культуры как феномена существован ия человеческого общества, сохранения духовных и материальных достижений человечества, в том числе и н епр еходящих цен ностей, опр еделяющихнаправленияразвития личности обучающегося.

Другие подходы - когнитивно-информационный, личностной и компетен тн остный - являются дополнительными и используются для решения кон кретных задач обучен ия.

Таким образом, культурологический подход символизирует ключевую идею обучения, которая определяет осн овные характеристики всех его составляющих, а также угол их интерпретации в оформлении и реализации образовательного пр оцесса.

Любая культура существует и передается через систему ценностей. То есть процесс обучения в соответствии с культурной парадигмой в целом может быть правомерно охарактеризован как процесс присвоения обучающимися системы ценностей иноязычной культуры, где все компоненты процесса - информация, деятельность и способы еереализации, достижен иен еобходимыхнавыков (компетенций), опыт индивидуальн ого общения на иностранном языке и т. д. приобретают характеристику «ценностное» [Оберемко 2015: 244].

Актуализация пон ятия культуры как базы исследования процессовразвития теории и практики образования в современных условиях понимается как модель, обусловленная социальным заказом на образование в постиндустриальном обществе, котор ое пер еживает глобальную научную революцию.

Рассматривая культуру как основное понятие в характеристике культурологической парадигмы обучения иностранному языку, важно рассматривать ее не только как способ общественного способа бытия, форму общественной жизни, но и как мировоззрение, образ мышления, ряд 
представлений или норм деятельности, которые сложились в социальной среде.

Идея культурной обусловленности образования выражается в принципе культурного соответствия. Центральным положением этого принципа является утверждение, что способы установления отношен ий человека с миром разрабатываются в рамках культурно-исторического полотна.

Современное понимание взаимосвязи образования и культуры основано на признании таких ключевых понятий, как «целостность», «свобода», «взаимодействие», «взаимозависимость», «вариативн ость», «культурный контекст образования» и т.п. Это позволяет признать, что обозначение «культур осообразная» по отношению к рассматриваемой парадигме подчеркивает социально-культурное значение обучения иностранному языку, способствуя доминированию пр осветительской модели формирования межкультурной компетенции, актуализируя, прежде всего, механизмы культурн ой адаптации обучающихся.

В соответствии с культурологической парадигмой процесс обучения теории и практики иностранного языка становится процессом овладения иноязычной культурой с присущими ей культурными кодами. Более полно, на мой взгляд, характер этого процесса отражает лингвистический и культурный аспект содержания обучения теории и практике ин остранн ого языка.

В последнее время в лингвистике зн ачительн ое вниман ие уделяется изучен ию человеческого фактора в языке - языку в связи с деятельн остью человека, человеку в языке и человеческой речи. Но конкретные лингвистические теории, полностью отражающие феномен человека, еще не разработаны. Причиной может быть отсутствие интегрирующей силы у всех четырех основных свойств языка: социальностьне подразумевает согласованности, исторический характерразвития не подразумевает психологической сущности языка, a его психологическая осн ова не обосн овывает его социальн ости.

В обучении такую интегрирующую функцию может выполн ять лингвострановедческий аспект содержания, изучающий языковой материал с ярко выраженной 
национ альной и культурной семантикой, наиболее полно и ярко отражающий культуру страны изучаемого языка.

Ключевое значение в контексте обучения теории и практике иностранного языка имеет лексика [Ильин 1992: 18]. Можн о заметить, что позн ан ие культуры чер ез слово в практике преподавания иностранных языков является наиболее реалистичным и эффективным.

Но не все обучающиеся смогут связать новое слово с полученными ими знаниями о культуре страны изучаемого языка. В то же время взаимосвязь нового слова с определенными реалиями и особенностями жизни и быта страны изучаемого языка является более естественным и доступным способом изучен ия культурной специфики языка.

Ознакомление с иноязычной реальностью на уроках иностранного языка происходит на основе всей совокупности страноведческих сведен ий, содер жащейся в учебных матер иалах и используемых в рамках образовательного процесса. Для передачи культурной информации, с одной стороны, важны языковые единицы с национально-культурными слагаемыми семантики. С другой стороны, для того чтобы представить всю совокупность страноведческих сведений, требуется широкий спектр лексики с межъязыковыми понятиями, чтобы обучающиеся могли выражать словами полученную страноведческую информацию и извлекать ее из аутентичных текстов.

Авторнастоящей статьи предлагает организовать лингвострановедческую информацию, используя категорию «образ жизни людей», в котор ой проводятся как национальнокультурные, реалии, так и фоновые знания. Лингвострановедческая информация при этом может быть различной в количественном и качественном отношении, в зависимости от стадии обучения, целей и задач обучения, готовн ости к изучен ию материала и т.

Важнейшей проблемой реализации культурологической парадигмы является определение соответствующих методов и технологий обучения. В связи с этим предлагаются методы, отвечающие смыслу этой парадигмы: определение страноведческого содержания текстов разного типа, языковой, лингвострановедческий коммен тарий, объяснение лексического 
и семантического фона. Современные технические средства также способствуют расширению организационных форм обучения.

\section{ЛИТЕРАТУР А}

1. Ильин Г.Л. Культур а и обр азован ие: поиски взаимн ого соответствия. - М.: ИЦППКС, 1992. - 78 с.

2. Милльр уд Р .П. Язык как символ культур ы // Язык и культур а,2013,№ 22. - С.44-61.

3. Обер емко О.Г. Аксиологический аспект пр еподаван ия ин остр ан н ого языка в языковом высшем учебн ом заведен ии // Вестник Н ГУ им. Н.И. Лобачевского. Сер ия: Социальн ые н ауки, 2015, № 39. - 242-248.

4. Тар ева Е.Г. Система подходов к пр еподаванию ин остр ан н ого языка в кон тексте культур осообр азн ости // Язык и культур а, 2017, № 30 . - C. 202-220.

(CФаткуллин И.Г., Батырова Г.3., Нуйкина М.P., 2021 г. 